\title{
The cost of business restrictions during the COVID-19
}

\section{pandemic [version 1; peer review: 2 approved with}

\section{reservations]}

Joshua T. Cohen, Samuel B. Weidner (iD)

Center for the Evaluation of Value and Risk in Health, Institute for Clinical Research and Health Policy Studies, Tufts Medical Center, Boston, MA, 02111, USA

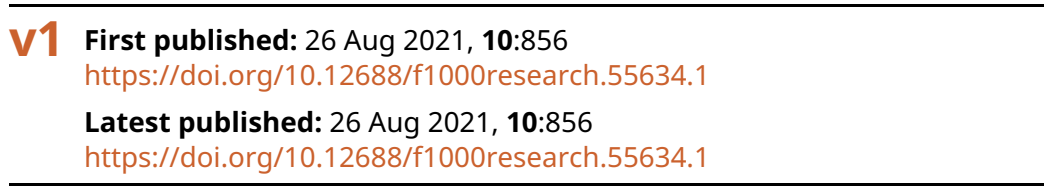

\section{Abstract}

Background: In addition to reducing mortality and morbidity, COVID19 therapies confer societal benefits by reducing the disease's economic impact. Therapies that address COVID hospitalizations mitigate the need for government-imposed economic restrictions to reduce disease spread and hence the risk that hospitals become overwhelmed. We investigated the potential value of such therapies by estimating the cost of government restrictions imposed during late 2020, costs that COVID therapies might make less necessary.

Methods: We combined high frequency consumer spending and initial unemployment claims data (outcomes), information about when state governments restricted business activities (explanatory variable of interest), and case incidence and mortality data (proxies for the potential confounding effect of pandemic severity on voluntary economic activity reductions). We developed linear mixed models that account for nesting within US state and correlation across observations close in time. Sensitivity analyses explored the impact of: (1) limiting attention to the 10 U.S. states that "mostly closed" at some point during late 2020; (2) excluding subsets of potential confounding variables; (3) altering our outcome variable definition (i.e., for designating a state as "mostly closed"); and (4) considering alternative model correlation structures.

Results: Government-imposed restrictions reduced total consumer spending by $2 \%$ and spending on restaurants and accommodations by $5 \%$. They increased weekly initial unemployment claims by $0.21 \%$ of the 2019 US workforce. We estimate that restrictions in the U.S. during late 2020 reduced consumer spending by $\$ 12$ billion and increased initial weekly unemployment claims by 114,000 . Sensitivity analyses indicated that our findings are robust.

Conclusions: Assuming that late 2020 is representative of tendencies for the government to restrict economic activity in response to high

\section{Open Peer Review}

Approval Status ? ?

12

version $1 ?$ ?

26 Aug 2021 view view

1. Franklin Dexter ID, University of Iowa, Iowa City, USA

2. Zeynep Kantur (ID), Başkent University, Ankara, Turkey

Any reports and responses or comments on the article can be found at the end of the article. 
hospital utilization, therapies reducing hospital utilization have the potential to confer substantial societal value. Recognizing societal benefits in health technology assessment will help allocate resources to address the most important risks society faces.

\section{Keywords}

COVID-19, cost, COVID-19 treatments, COVID-19 therapies, economics, business restrictions, consumer spending, unemployment claims, hospital utilization

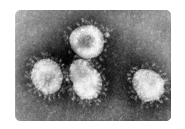

This article is included in the Coronavirus

\section{collection.}

\section{Corresponding author: Joshua T. Cohen (jcohen@tuftsmedicalcenter.org)}

Author roles: Cohen JT: Conceptualization, Formal Analysis, Funding Acquisition, Investigation, Methodology, Resources, Supervision, Writing - Original Draft Preparation, Writing - Review \& Editing; Weidner SB: Data Curation, Formal Analysis, Methodology, Project Administration, Software, Validation, Visualization, Writing - Original Draft Preparation, Writing - Review \& Editing

Competing interests: Joshua Cohen is employed by Tufts Medical Center and discloses receiving personal fees from these other life sciences companies for work not related to this paper: Biogen, IQvia, Novartis, Partnership for Health Analytic Research, Precision Health Economics, Sage Pharmaceuticals, Sanofi, and Sarepta. Samuel Weidner is employed by Tufts Medical Center.

Grant information: The Center for the Evaluation of Value and Risk in Health at Tufts Medical Center received financial support for this work from the following companies, all of which have or are developing COVID-19 vaccines or therapies: AstraZenica, Bristol Myers Squibb, Eli Lilly, Gilead Sciences, Johnson \& Johnson, Merck, Pfizer, and Regeneron.

The funders had no role in study design, data collection and analysis, decision to publish, or preparation of the manuscript.

Copyright: (c) 2021 Cohen JT and Weidner SB. This is an open access article distributed under the terms of the Creative Commons Attribution License, which permits unrestricted use, distribution, and reproduction in any medium, provided the original work is properly cited.

How to cite this article: Cohen JT and Weidner SB. The cost of business restrictions during the COVID-19 pandemic [version 1; peer review: 2 approved with reservations] F1000Research 2021, 10:856 https://doi.org/10.12688/f1000research.55634.1

First published: 26 Aug 2021, 10:856 https://doi.org/10.12688/f1000research.55634.1 


\section{Introduction}

COVID's most notable impact has been illness and the loss of life, but the pandemic has also imposed a substantial societal cost. The economy has grabbed headlines, as cumulative losses during just the first two quarters of 2020 amounted to between 1 and 7\% of annual GDP across the globe, and approximately 3\% of annual GDP in the United States. ${ }^{1}$ Other societal costs include reduced care for health conditions other than COVID, ${ }^{2,3}$ although that impact may have been largely limited to the initial several months of the pandemic. ${ }^{4}$ Finally, evidence suggests that lost in-person schooling will permanently diminish economic opportunities for today's students; moreover, the impact is greatest for students from the most disadvantaged backgrounds. ${ }^{5}$

The pandemic's economic costs suggest that COVID-19 medical interventions could confer societal benefits exceeding the value of their health benefits. ${ }^{6}$ Based on stock market movements in apparent response to positive news about vaccines in development, for example, one analysis estimated a pandemic-ending therapy to be worth between 5 and $15 \%$ of total wealth. ${ }^{7}$ In the United States alone, that result implies a value ranging from $\$ 6$ to $\$ 17$ trillion. ${ }^{8}$

Assessing the societal value of COVID therapies that have a less dramatic impact on the population as a whole, such as antiviral treatments ${ }^{9}$ and monoclonal antibodies, ${ }^{10}$ presents a distinct challenge. These therapies do not directly address population disease transmission and therefore have less potential to return life to "normal". Instead, they aim to prevent progression to severe disease or speed recovery.

We hypothesize that these clinical benefits, if the data hold up, nonetheless confer a societal benefit by diminishing the need for government-imposed restrictions on economic activity designed to increase social distancing. By "flattening the curve", economic restrictions and other distancing measures aim in part to prevent the health care system from becoming overwhelmed. ${ }^{11,12}$ The link between hospital utilization in particular and government-imposed restrictions seems evident in headlines from late 2020. For example, one headline noted, "If NY hospitals get overwhelmed, state could shut down again, Cuomo says". ${ }^{13}$ Another stated, "California's Governor Warns of 'Drastic Action' as Hospitals Near Crisis". ${ }^{14}$ A December 3 executive order outlined economic restrictions in California when a region's free intensive care unit capacity dropped below $15 \%$-including a ban on hotel stays for out-of-state guests, suspension of indoor dining at restaurants, and a $20 \%$ capacity limit on retail establishments. ${ }^{15}$ When Massachusetts governor, Charlie Baker, loosened business restrictions toward the end of January 2021, he identified a drop in COVID hospitalizations as a key factor informing his decision. ${ }^{16}$

Because high hospital utilization levels trigger restrictions, therapies that reduce hospitalizations or hospital length of stay can also reduce the need for restrictions. This paper's aim is to estimate the cost of these restrictions and hence the potential value conferred by COVID-19 therapies that help avert hospital admissions by preventing progression to severe disease or that speed recovery.

\section{Methods}

To assess the cost of government-imposed economic restrictions, we combined high frequency economic data, information on the pandemic's progression (case incidence and mortality), and information about when state governments imposed and lifted restrictions on business activities. Rather than including data from spring, 2020, when the pandemic's initial onslaught increased unemployment claims and reduced consumer spending to an extent unrepresentative of subsequent periods during the pandemic, ${ }^{17,18}$ we instead focused on the fall and winter of 2020-2021. All of the analysis was conducted in R v4.0.3, utilizing the R nlme package for regression analysis (R package: nlme, RRID: SCR_015655).

Descriptive statistics: We report the number of observations, mean, and standard deviation for all outcome quantities and all explanatory variables. We stratify the data by the level of regulatory measures in place during that week. As described below (see Data), we classify each U.S. state during each week as either "mostly closed" due to governmentimposed activity restrictions, or as not "mostly closed."

Base case analysis: We used regression to predict the influence of restrictions on consumer spending and weekly initial unemployment claims. We controlled for daily COVID case count, COVID mortality, and the change in these two rates over the preceding two weeks. More formally, we developed three sets of models, one set for each of three outcomes: ${ }^{1}$ percent change since January, 2020 in total seasonally adjusted consumer spending, ${ }^{2}$ percent change in seasonally adjusted consumer spending on restaurants and accommodations since January, 2020, and ${ }^{3}$ weekly unemployment claims (not seasonally adjusted) as a percent of the 2019 US workforce.

Our base case regression specification models each outcome as,

Outcome $_{i}^{s}=\alpha+\beta_{1}$ Restricted $_{i}^{s}+\beta_{2}$ NewCases $_{i}^{s}+\beta_{3}$ DeltaNewCases $_{i}^{s}+\beta_{4}$ NewDeaths $_{i}^{s}+\beta_{5}$ DeltaNewDeaths $_{i}^{s}$, 
where the subscript $i$ denotes the week and the superscript $s$ denotes one of the 50 U.S. states (and Washington, D.C. for the initial unemployment claims). Explanatory variables included $\operatorname{Restricted}_{i}^{s}$ (a binary variable indicating if state $s$ was "mostly closed" during week $i$; see data sources below); NewCases ${ }_{i}^{s}$ and NewDeaths ${ }_{i}^{s}$, which refer to state-specific, population-normalized daily case incidence and mortality; and DeltaNewCases ${ }_{i}^{s}$ and DeltaNewDeaths ${ }_{i}^{s}$, which refer to state-specific, population-normalized changes in these values over the last two weeks. We included the COVID case and mortality rates, and their rate of change to address the possibility that reduced economic activity may in part be due to voluntary disengagement from the economy in response to reports of higher rates of COVID illness and death.

All regressions are linear mixed models that account for nesting within state and correlation across observations that are close in time. To account for temporal correlation, the base case model implemented a first-order, autoregressive (lag 1-week) covariance structure. This covariance structure assumes correlation is greatest for observations adjacent in time, with decreasing correlation between observations more distant in time.

Sensitivity analysis: We conducted a series of sensitivity analyses to explore how alternative assumptions influence our conclusions.

First, we conducted an analysis limited to the 10 states designated "mostly closed" at some point between September 15 through December 27, 2020 (California, Kentucky, Illinois, Michigan, Minnesota, New Mexico, Oregon, Pennsylvania, Rhode Island, and Washington).

Second, we explored alternative model specifications that omitted some of the explanatory variables in the base case model, including ${ }^{1}$ the daily COVID mortality rate, ${ }^{2}$ the daily COVID case rate, or $^{3}$ both the case rate and the mortality rate. We conducted this sensitivity analysis because inclusion of the case rate and mortality rate in the regression model may lead to "over-control" of phenomena correlated with government restrictions, and that could artificially reduce the estimated impact of government restrictions on economic activity. This set of sensitivity analyses explores the potential magnitude of this type of potential error.

Third, we considered alternative criteria for designating a week as subject to government-imposed restrictions. The first alternative designates a state as subject to restrictions only after restrictions have been in place for at least 14 days. This alternative explores the potential for a lag (of two weeks) between a state's imposition of restrictions and the impact of those restrictions on economic activity. For example, if a state enacted restrictions from the $1^{\text {st }}$ to the $21^{\text {st }}$ of October, this sensitivity analysis designates the week of October $1^{\text {st }}$ and the week of October $8^{\text {th }}$ as not Restricted, but designates the week of October $15^{\text {th }}$ as Restricted. The second alternative recognizes only those restrictions that remain in place for at least three weeks. For the preceding example, that would mean that all three weeks (starting October $1^{\text {st }}$, October $8^{\text {th }}$, and October $15^{\text {th }}$ ) would be designated as Restricted. On the other hand, if the state had imposed restrictions from October $1^{\text {st }}$ to October $20^{\text {th }}$ (just under 3 weeks), this sensitivity analysis would designate all three weeks as not Restricted. That is, we treat states imposing only restrictions shorter than three weeks in duration as unrestricted at all times. The third alternative set of criteria recognizes only those restrictions that include a complete ban on indoor dining at restaurants.

Finally, we considered alternative model correlation structures, including $2^{\text {nd }}, 3^{\text {rd }}$, and $4^{\text {th }}$ order autoregressive models (i.e., $\mathrm{AR}^{2}, \mathrm{AR}^{3}$, and $\mathrm{AR}^{4}$ ), $1^{\text {st }}$ and $2^{\text {nd }}$ order moving average (i.e., $\mathrm{MA}^{1}$ and $\mathrm{MA}^{2}$ ), and a series of autoregressivemoving average models (ARMA) with different combinations of first- and second-order AR and MA components (i.e., AR1MA1, AR1MA2, AR2MA1, and AR2MA2).

We report the Akaike Information Criterion (AIC) statistic as an indicator of goodness of fit for each model (lower or more negative values indicate better fit).

Data: We report our time series data as weekly values. For spending data reported by the original source as daily sevenday moving averages, we retained one value from each seven-day period to represent that week.

Outcomes - Outcomes data come from the Opportunity Insights COVID-19 Economic Tracker project at Harvard University. ${ }^{19,20}$ The Opportunity Insights Economic Tracker data repository sourced its spending data from Affinity Solutions, and its initial unemployment claims data from the Department of Labor. Selection of these outcomes reflects the expectation that government restrictions affect consumer spending in general and restaurant dining and accommodations in particular. These impacts, in turn, contribute to higher initial unemployment claims.

For state $s$ and week $i$, outcomes include percent change in seasonally adjusted spending on restaurants and accommodations compared to January $2020\left(\right.$ SpndRst $\left._{i}^{S}\right)$, and percent change in seasonally adjusted total consumer spending 
compared to January $2020\left(\operatorname{SpndTt} l_{i}^{S}\right)$. To eliminate weekend and weekday periodicity, the Opportunity Insights Economic Tracker group computed seven-day moving average values for the spending data, as described above. To eliminate effects of state size, they also normalized all spending values by population size. The spending data span the period September 15 to December 27, 2020. Our third outcome, for state $s$ and week $i$, was initial unemployment claims (reported on Thursday of each week) per 100 people in the 2019 labor force $\left(U E_{i}^{s}\right)$. This data series spanned the period September 19 to December 19, 2020.

High frequency data are well suited to assessing restrictions imposed at moderately different times across states and remaining in effect for durations often measured in weeks during the fall and winter of 2020-2021. Moreover, because states imposed and lifted these restrictions only shortly before we conducted our analysis, frequently updated data best cover salient periods. Conventional economic activity datasets, like government estimates of gross domestic product (GDP) growth, undergo updating too infrequently to assess the impact of short-term restrictions and the recent imposition of restrictive government measures.

Explanatory variables - As with outcomes, we index explanatory variables by state $s$ and week $i$. Our primary explanatory variable of interest, designated Restricted ${ }_{i}^{s}$, is binary. We classified state businesses as restricted or not restricted based on narrative descriptions of state-level closures maintained by the New York Times, which reported for each day whether businesses in each state were "mostly closed." ${ }^{21}$ Based on review of these narratives, we identified when each state changed from not "mostly closed" to "mostly closed", or the reverse. Our base case analysis designated business in a state as "restricted" during week $i$ if, according to the New York Times database, businesses were "mostly closed" on Monday (for the consumer spending outcomes) or Thursday (for the initial unemployment claim outcome) of that week.

We included other explanatory variables in an effort to account for how news about the pandemic might influence voluntary, spontaneous reductions in economic activity. These variables included seven-day average, populationnormalized $^{1}$ daily new COVID cases $\left(\right.$ New Cases $\left._{i}^{s}\right),{ }^{2}$ daily COVID mortality $\left(\right.$ NewDeaths $\left.{ }_{i}^{s}\right),{ }^{3}$ the increase in daily new COVID cases over the last two weeks (DeltaNewCases ${ }_{i}^{s}$ ), and ${ }^{4}$ the increase in daily COVID mortality over the last two weeks (DeltaNewDeaths ${ }_{i}^{s}$ ). Daily COVID cases and deaths were provided from the New York Times COVID-19 Repository to the Opportunity Insights Economic Tracker data repository. ${ }^{22}$

\section{Results}

Descriptive statistics: Table 1 summarizes the data. Outcomes (consumer spending, unemployment claims) are more favorable during weeks without restrictions (first three numeric columns) than during weeks with restrictions (last three numeric columns). Case counts and mortality are lower during weeks without restrictions than during weeks with restrictions. The rate at which case counts grow (increase per two-week period) is higher during weeks without restrictions. On the other hand, the change in mortality is similar across these two sets of weeks.

Base case analysis: Table 2 reports regression analysis results for our base case models. The estimated impacts of government-imposed restrictions (row labeled "Restricted") are statistically significant and in the expected direction for all three outcomes - i.e., a reduction in consumer spending, a reduction in restaurant and accommodations spending, and an increase in initial unemployment claims.

Sensitivity analysis: Our first sensitivity analysis (Table 3) explored the impact of restricting attention to the 10 states that all experienced periods during which the government imposed restrictions and other periods during which the government did not impose restrictions. For these 10 states, government restrictions had the same impact on total consumer spending (coefficient of -0.02 for Restricted, i.e., a $2 \%$ reduction) as they had for all 50 states (Table 2). The impacts on restaurant and accommodations spending (coefficient of -0.04 in Table 3 vs. coefficient of -0.05 in Table 2) and on initial unemployment claims (coefficient of 0.20 in Table 3 vs. coefficient of 0.21 in Table 2) were slightly smaller than the corresponding impacts in the base case.

Tables 4, 5, and 6 show results for the second set of sensitivity analyses - i.e., for alternative models that do not control for COVID case rate, COVID mortality, or both. The impacts of government restrictions on total consumer spending (Table 4) remain similar to the corresponding base case impacts (coefficient of around -0.02). Impacts on restaurant and accommodations spending (Table 5) likewise remain similar to the corresponding base case impacts (coefficient of around -0.05). For initial weekly unemployment claims (Table 6), not controlling for case rate and death rate modestly increased the estimated impact of restrictions on initial unemployment claims to 0.25 percent of the 2019 workforce from 0.21 percent in the base case. 
Table 1. Summary statistics.

\begin{tabular}{|c|c|c|c|c|c|c|}
\hline & \multicolumn{3}{|c|}{$\begin{array}{l}\text { During weeks without } \\
\text { restrictions }\end{array}$} & \multicolumn{3}{|c|}{$\begin{array}{l}\text { During weeks with } \\
\text { restrictions }\end{array}$} \\
\hline & $\mathbf{N}^{\mathrm{d}}$ & Mean & SD & $\mathbf{N}^{\mathrm{d}}$ & Mean & SD \\
\hline \multicolumn{7}{|l|}{ Outcomes } \\
\hline Change - total consumer spending ${ }^{a}$ & 689 & -0.02 & 0.07 & 49 & -0.07 & 0.05 \\
\hline Change - restaurant and accommodation spending ${ }^{a}$ & 689 & -0.27 & 0.10 & 49 & -0.43 & 0.06 \\
\hline Initial weekly unemployment claims ${ }^{b}$ & 660 & 0.43 & 0.28 & 41 & 0.78 & 0.43 \\
\hline \multicolumn{7}{|l|}{ Explanatory variables } \\
\hline Restricted & 689 & 0 & 0.00 & 49 & 1 & 0.00 \\
\hline Case rate $^{c}$ & 689 & 40 & 30 & 49 & 66 & 28 \\
\hline Mortality $^{c}$ & 689 & 0.44 & 0.40 & 49 & 0.84 & 0.43 \\
\hline Change in case rate over last two weeks & 689 & 0.32 & 0.44 & 49 & 0.13 & 0.43 \\
\hline Change in mortality over last two weeks & 689 & 0.40 & 1.06 & 49 & 0.47 & 0.49 \\
\hline
\end{tabular}

apercent change in spending compared to January 2020.

${ }^{\mathrm{b}} \mathrm{Claims}$, as a percentage of the 2019 labor force.

Seven-day moving average, number per 100,000 state population.

${ }^{\mathrm{d}}$ Missing values: The original dataset included 750 observations for total consumer spending and for spending on restaurants and accommodations (50 states, 15 weeks). We removed 12 observations because zero reported deaths during the index week meant we could not compute a percent change in deaths over the following two weeks. The 12 missing observations included 1 observation for ME, 10 for VT, and 1 for WY. For initial unemployment claims, the original dataset included 714 observations (50 states plus DC, 14 weeks). We removed 13 observations for the same reason as described above for spending, including 1 observation for $\mathrm{ME}, 1$ for $\mathrm{NH}, 10$ for $\mathrm{VT}$, and 1 for WY. All removed observations come from weeks without restrictions. These missing values represent less than 2 percent of our original sample, and a substantially smaller fraction of U.S. GNP. We therefore took no action to provide values for these missing observations.

Tables 7, 8, and 9 present regression model results for the third set of sensitivity analyses, which explore alternative definitions for the Restricted variable. Models designating weeks as Restricted only after two weeks following enactment of state-imposed distancing measures (left panels in Tables 7, 8, and 9) estimated that government restrictions had smaller estimated impacts than the corresponding impacts in our base case model. In Table 7, the left panel coefficient for Restricted is -0.01 , compared to -0.02 for the corresponding base case coefficient in Table 2 . In Table 8 , the left panel coefficient for Restricted is -0.02 , compared to -0.05 for the corresponding base case coefficient in Table 2 . In Table 9 , the left panel coefficient for Restricted is 0.04 , compared to 0.21 for the corresponding base case coefficient in Table 2. As detailed in the last rows in Tables 7, 8, and 9, these models had higher AIC values than the base case model, indicating that they do not fit the data as well as the base case model.

Finally, we report results for other model correlation structures (Tables 10,11, and 12). Not all alternative correlation structures we evaluated produced models that converged. For those that did, the estimated impacts of governmentimposed restrictions were similar to or modestly larger than the corresponding base case estimates. The AIC goodness of fit statistics indicate, however, that models that produced estimates for the impact of government-imposed restrictions that differed the most from the corresponding base case estimates did not fit the data as well as the base case model (less negative AIC value).

\section{Discussion}

We found that government-imposed restrictions during the fall and early winter of 2020-2021 were associated with reduced economic activity. Descriptive statistics revealed lower total consumer spending, lower consumer spending on restaurants and accommodations, and a greater number of initial unemployment claims during weeks with restrictions than during weeks without restrictions (Table 1 - compare outcome means for weeks without and with restrictions). Regression analysis revealed an association with restrictions even after controlling for the number of new COVID cases, COVID mortality, and the change in those rates over the preceding two weeks (Table 2). That influence appears to be robust to modeling assumptions, as indicated by the modest impact of our sensitivity analyses on the estimated impact of government-imposed restrictions. Where sensitivity analyses yielded the most notable departures from the base case, the AIC value suggested the alternative model did not fit the model as well.

Several factors complicated assessment of the impact of government restrictions on economic outcomes. Importantly, the restrictions imposed by state governments differed across states and over time. Our sensitivity analyses using alternative 

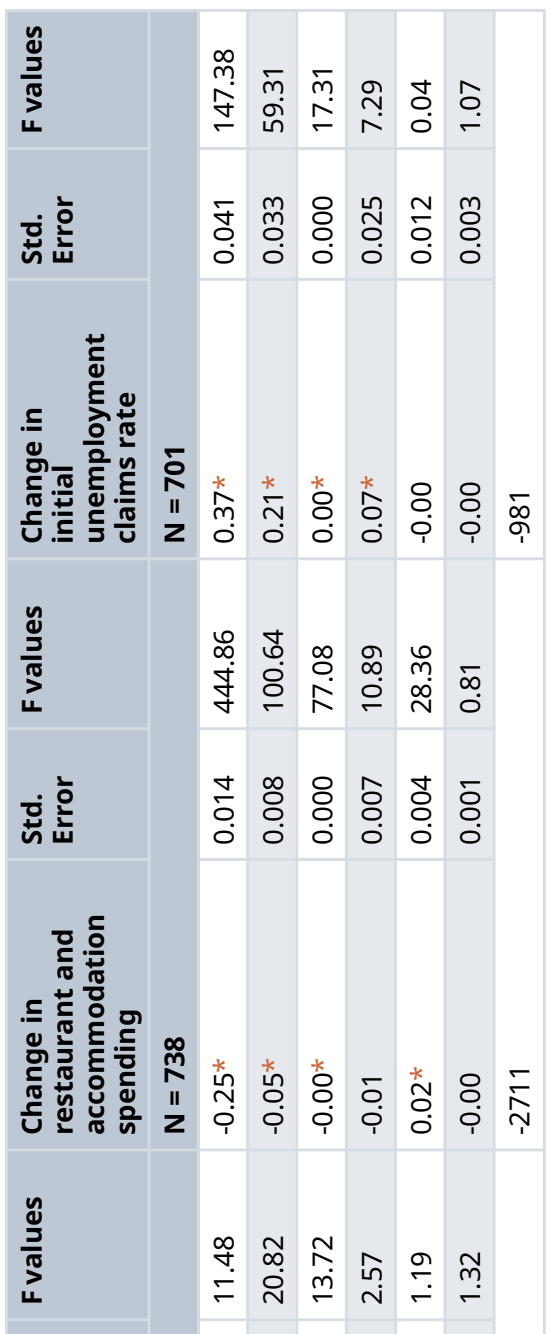

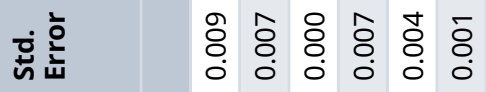
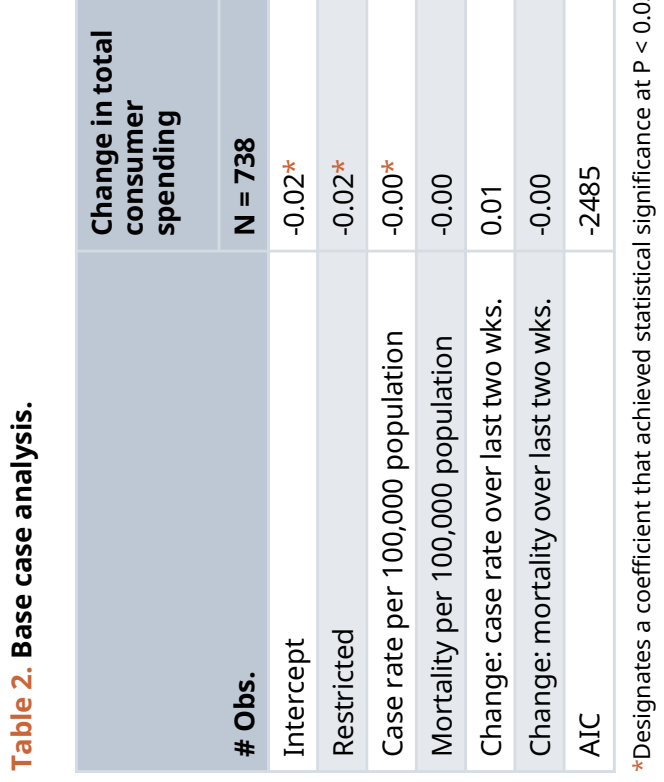
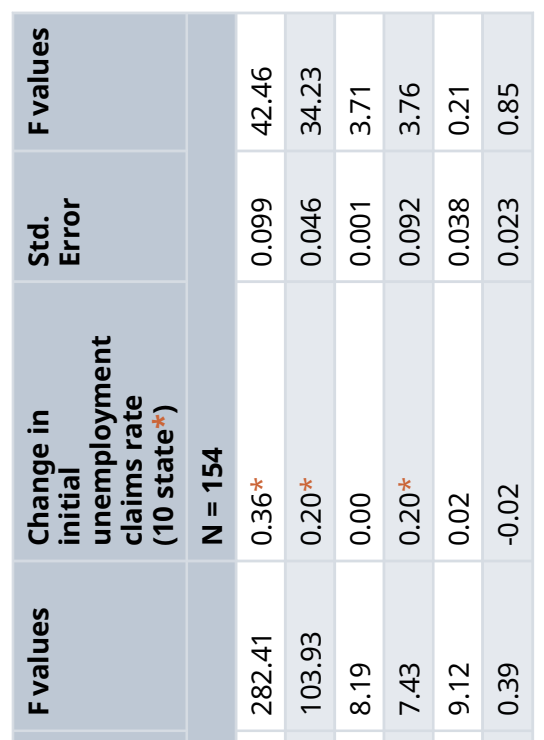

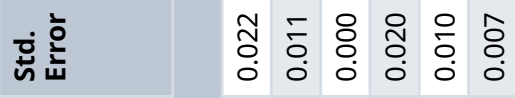

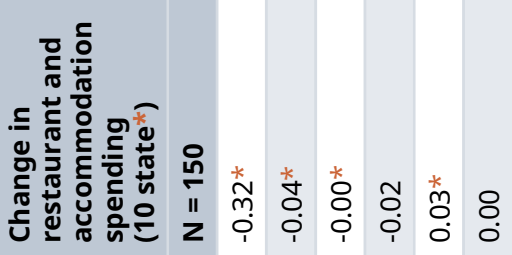

$\frac{y}{\frac{5}{7}}$

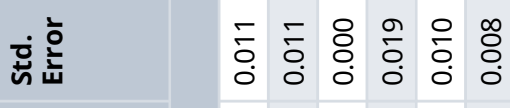

Гٓ

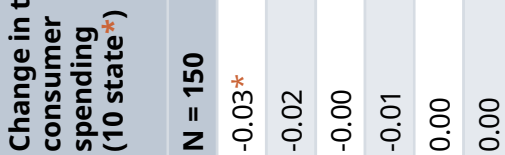

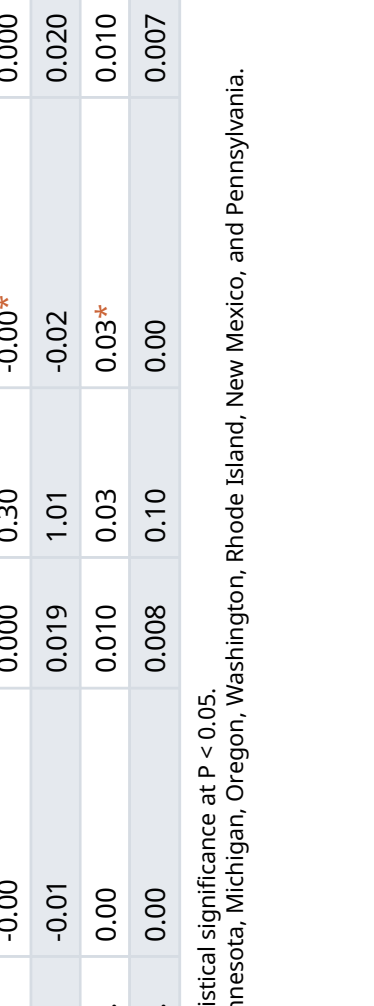

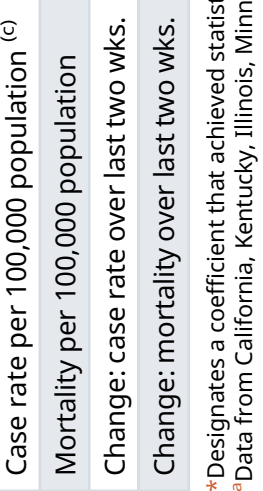




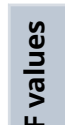

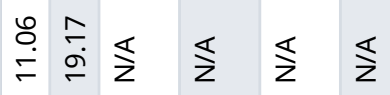

离京

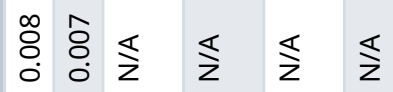

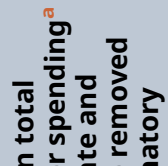

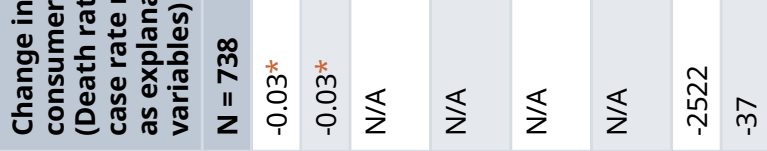

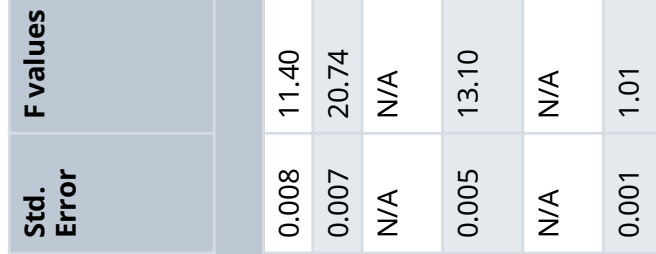

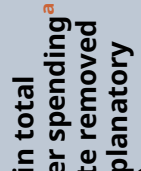

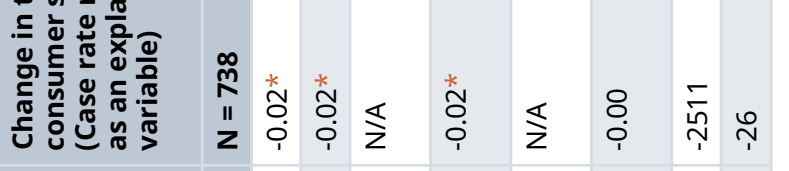

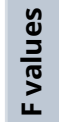

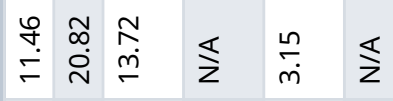

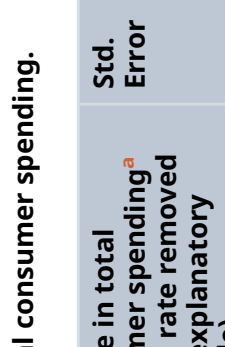

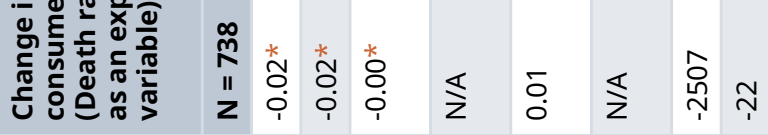

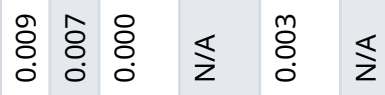

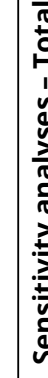

$\frac{y}{\frac{y}{5}}$

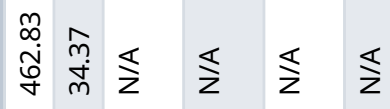

它京

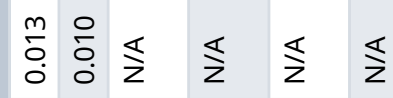

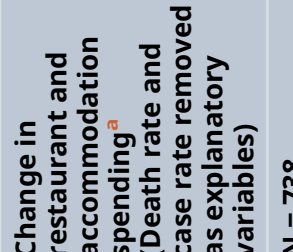

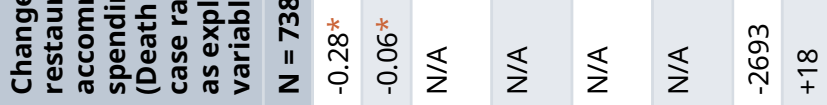

$\frac{\stackrel{y}{\pi}}{\frac{\pi}{5}}$

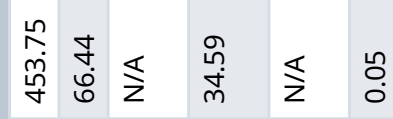

它京

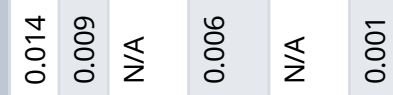

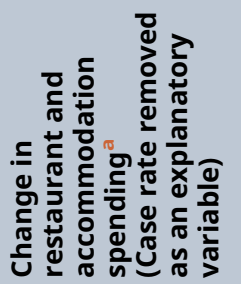

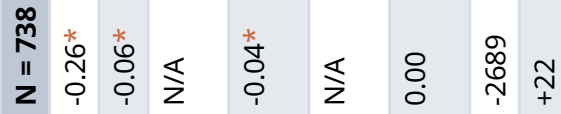

$\sum_{\frac{1}{5}}^{\frac{y}{5}}$

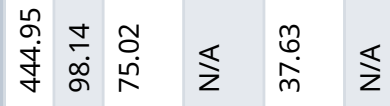

它京

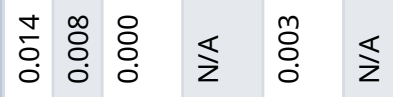

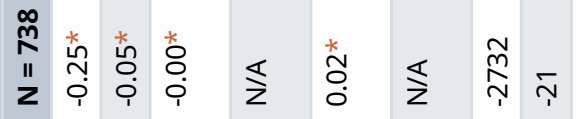

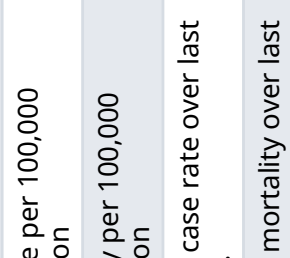

范

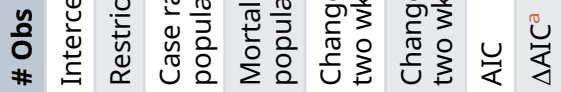


$\sum_{\frac{1}{5}}^{\frac{y}{5}}$

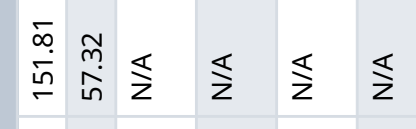

安率

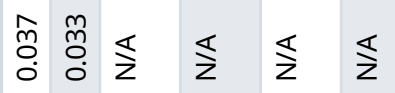

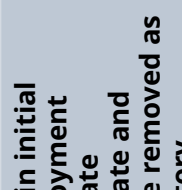

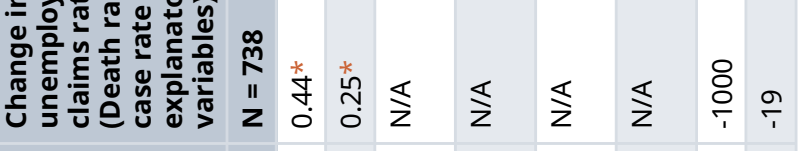

$\frac{\mathscr{y}}{\frac{\mathscr{m}}{\mathrm{N}}}$

畐高

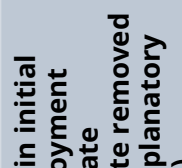

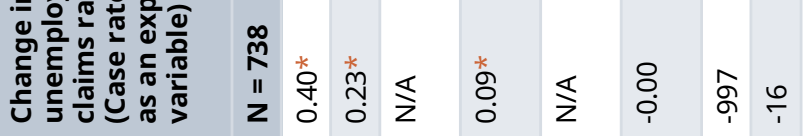

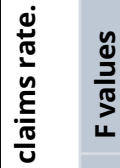

离

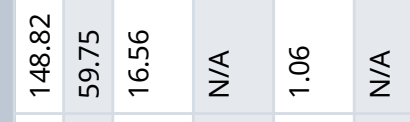

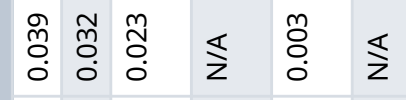

苍 离

응

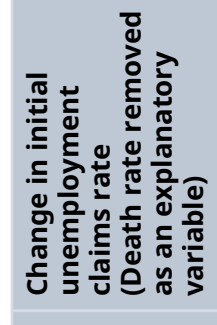

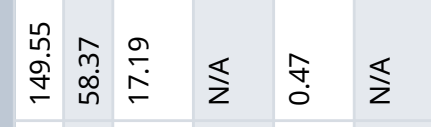

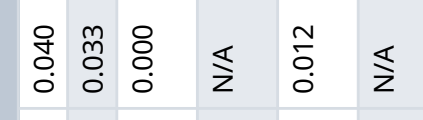

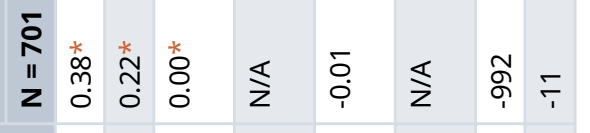

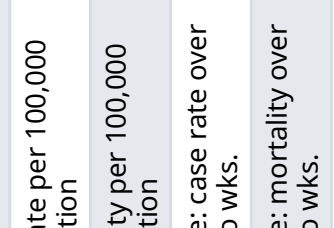

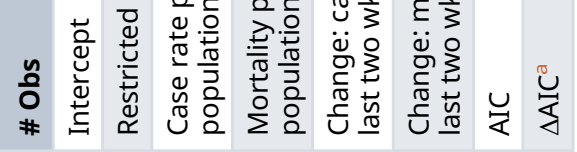
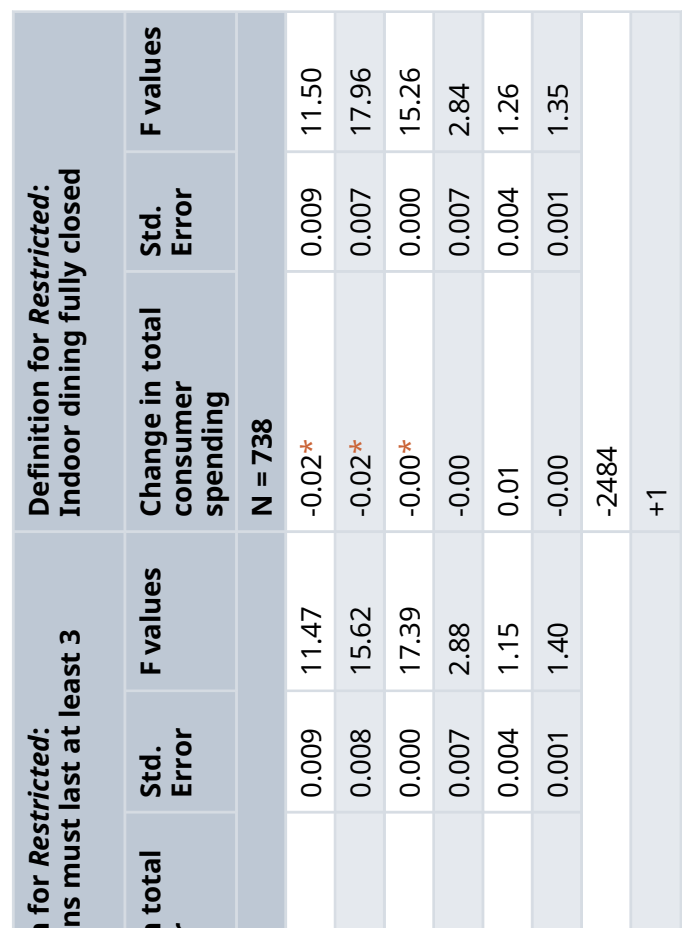

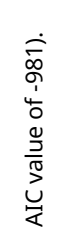

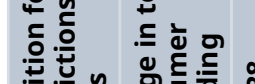

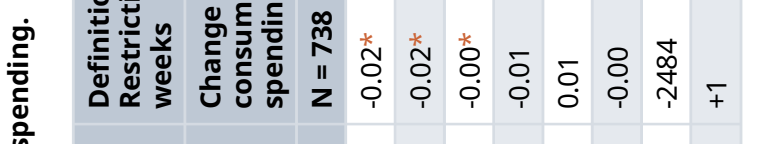

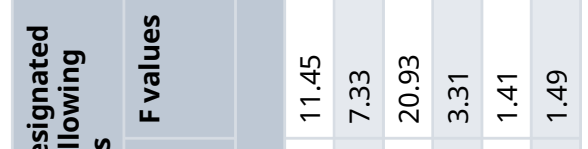

는 는 는

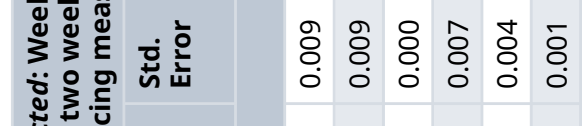

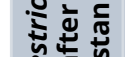

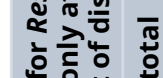

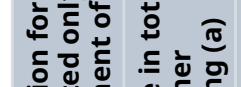

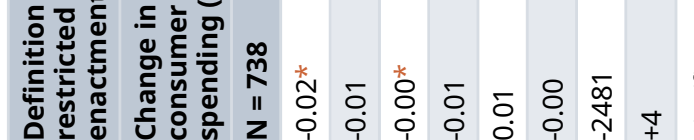

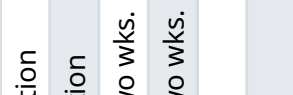

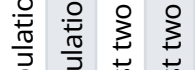

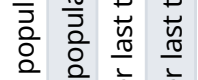

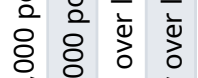

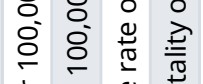

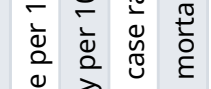

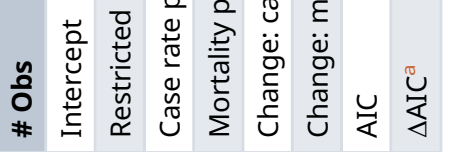



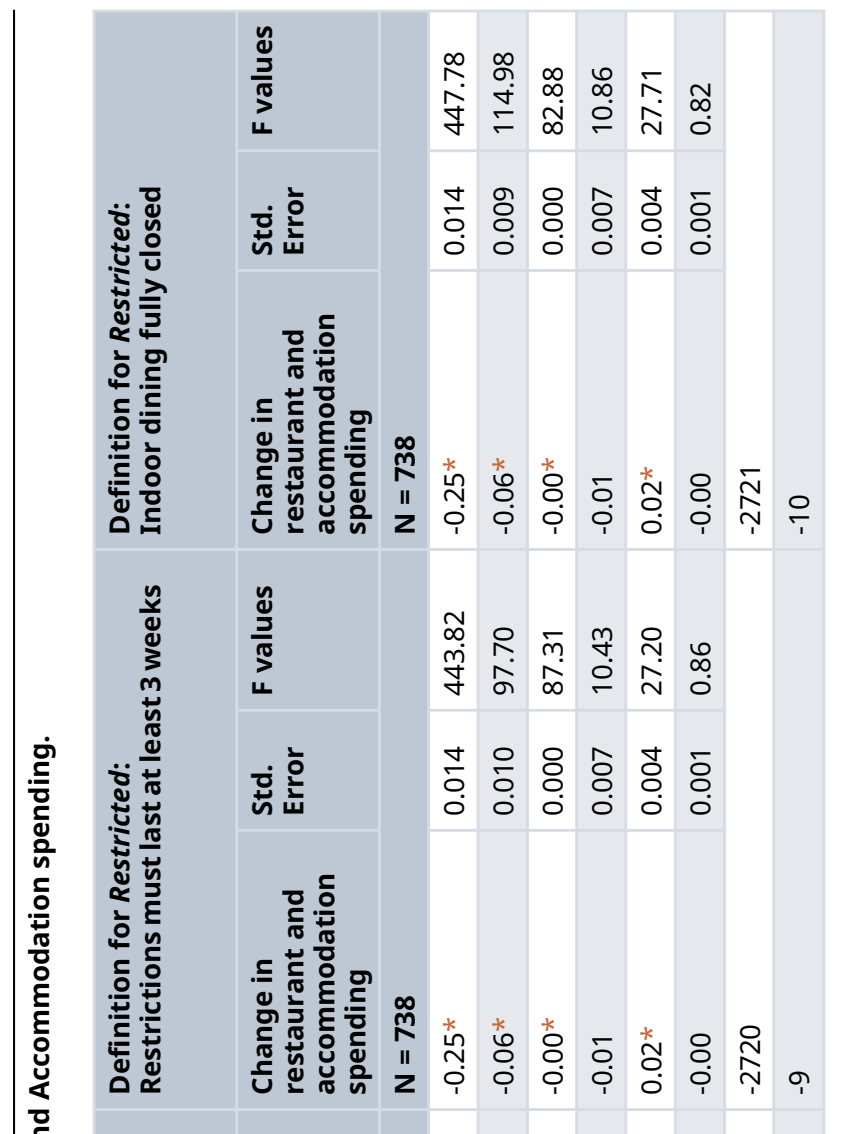

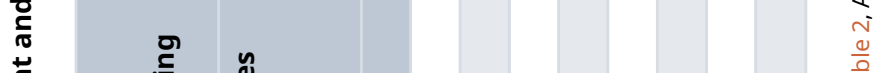

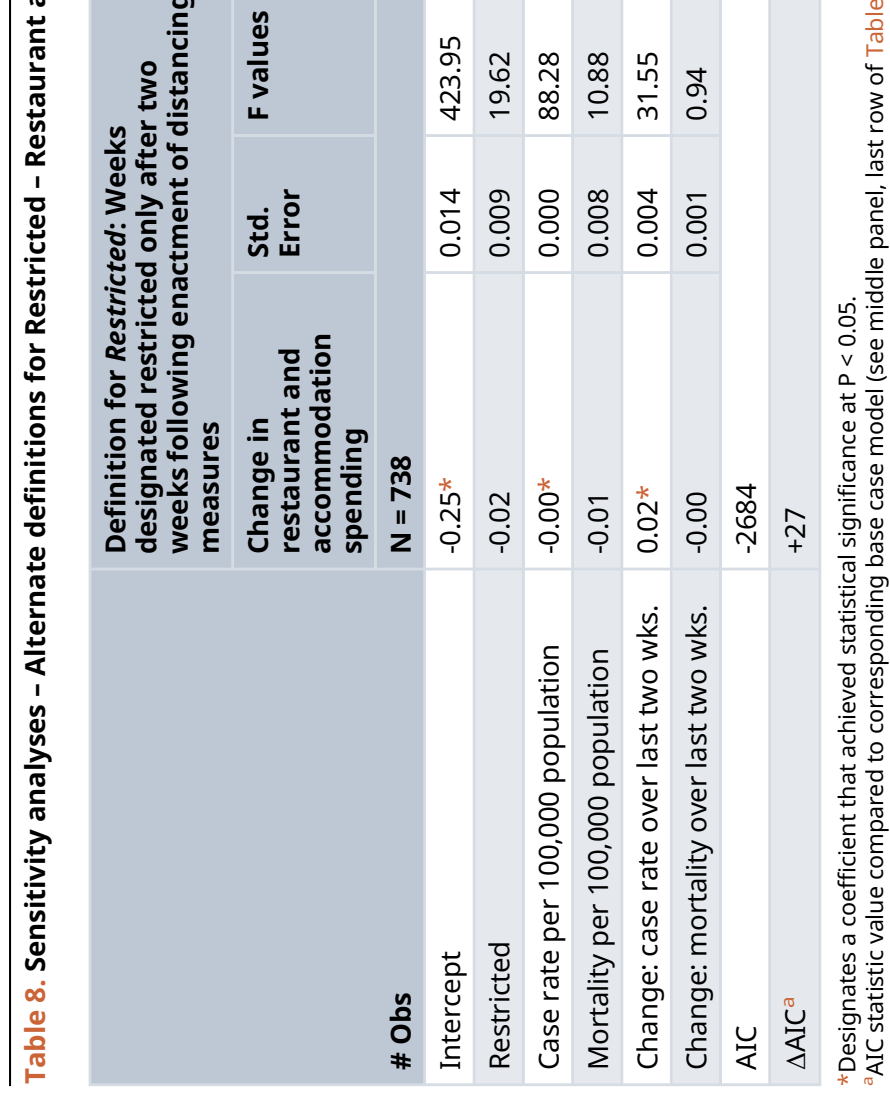

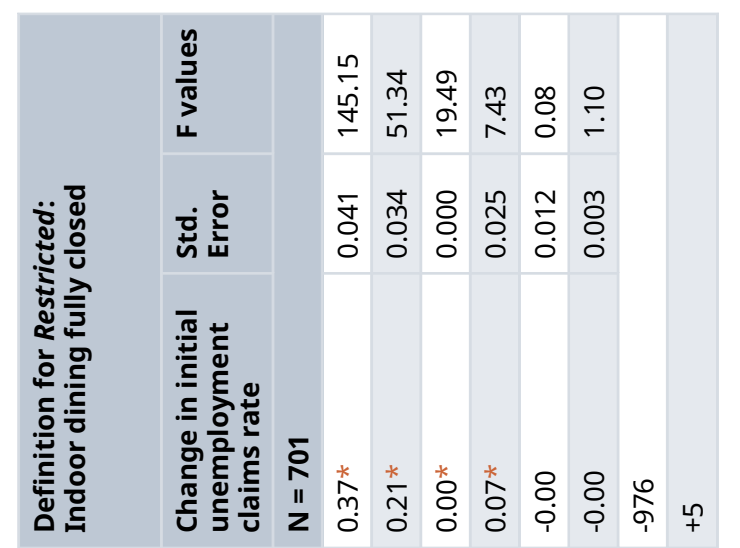

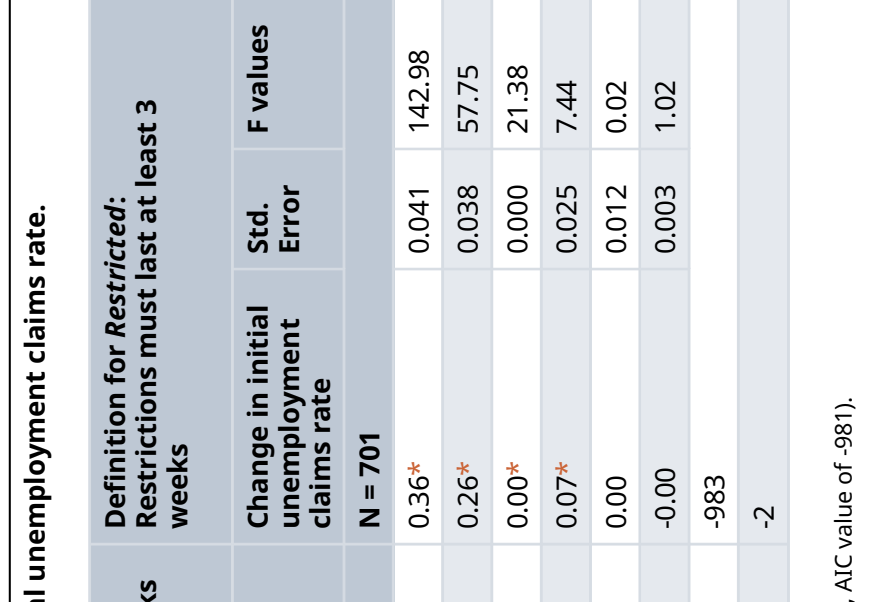

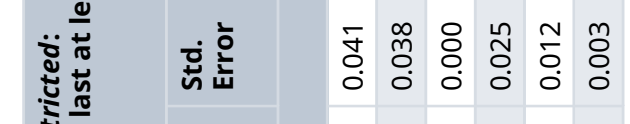

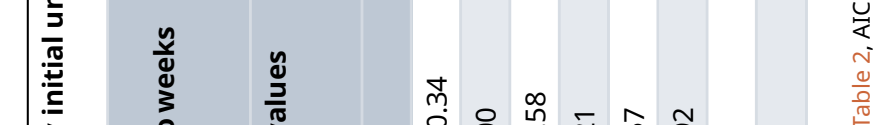
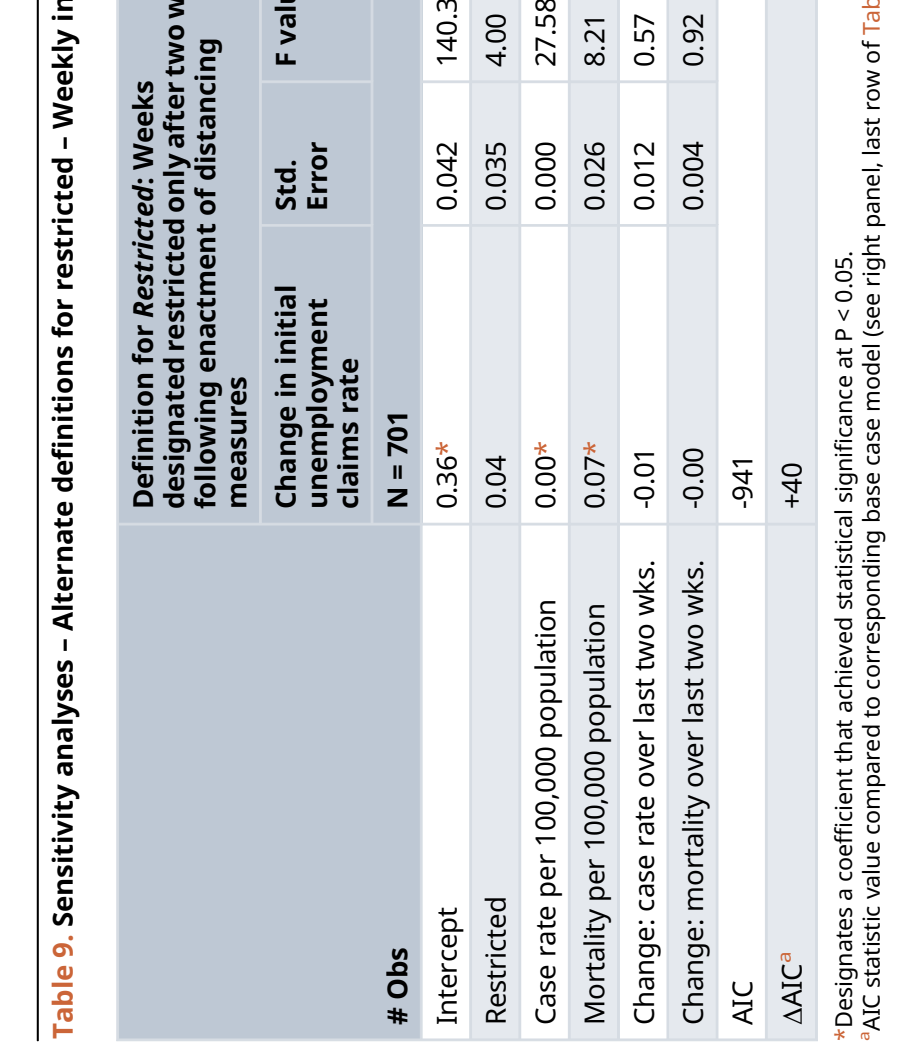


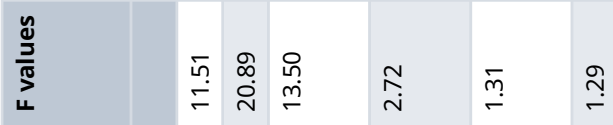

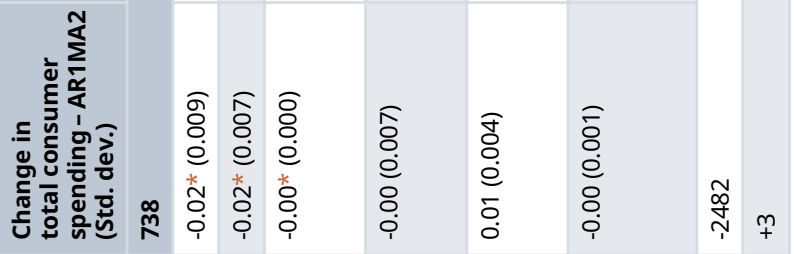

$\frac{\sqrt[n]{5}}{\frac{5}{5}}$

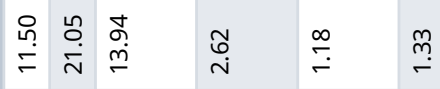

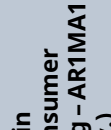

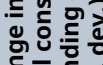

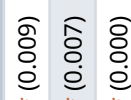

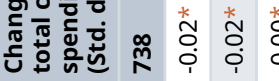

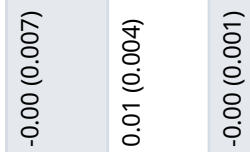

$\stackrel{\substack{\infty \\ \stackrel{o}{\sim}}}{\sim}$

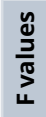

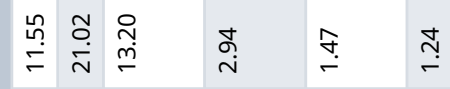

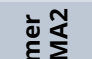

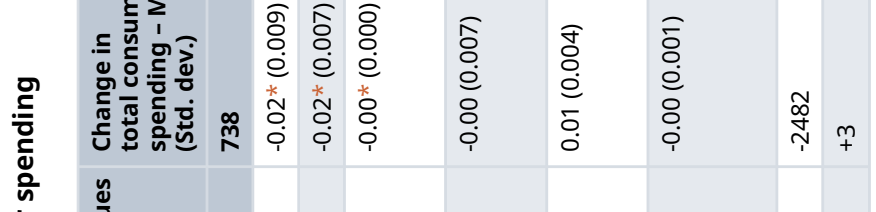

$\frac{\mathscr{m}}{\frac{\pi}{5}}$

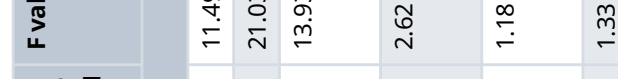

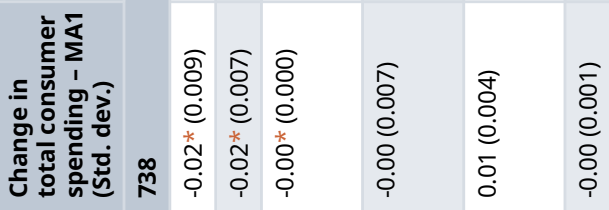

$\frac{\sqrt{2}}{\frac{2}{5}}$

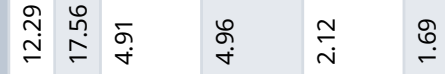

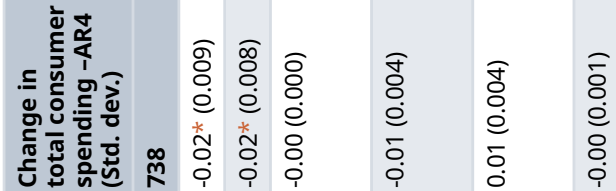

$\frac{\sqrt[4]{5}}{\frac{2}{2}}$

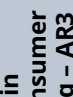

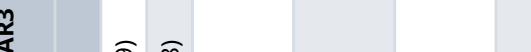

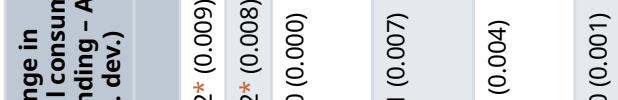

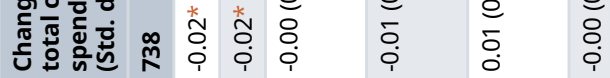

$\frac{\mathscr{4}}{\frac{\pi}{2}}$

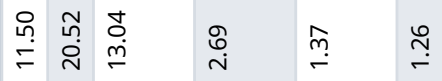

离

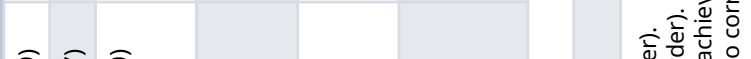

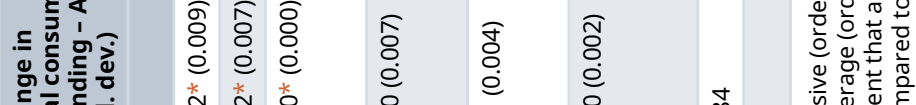

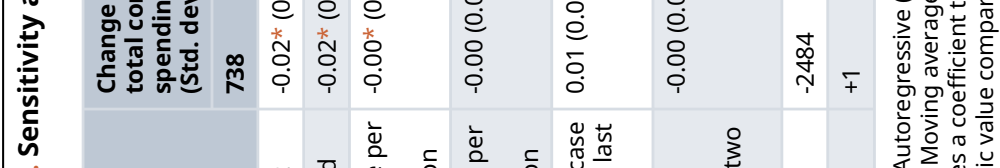

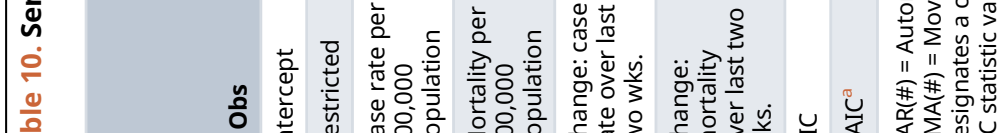

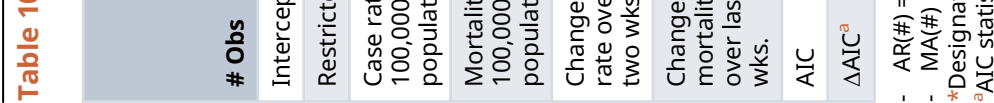




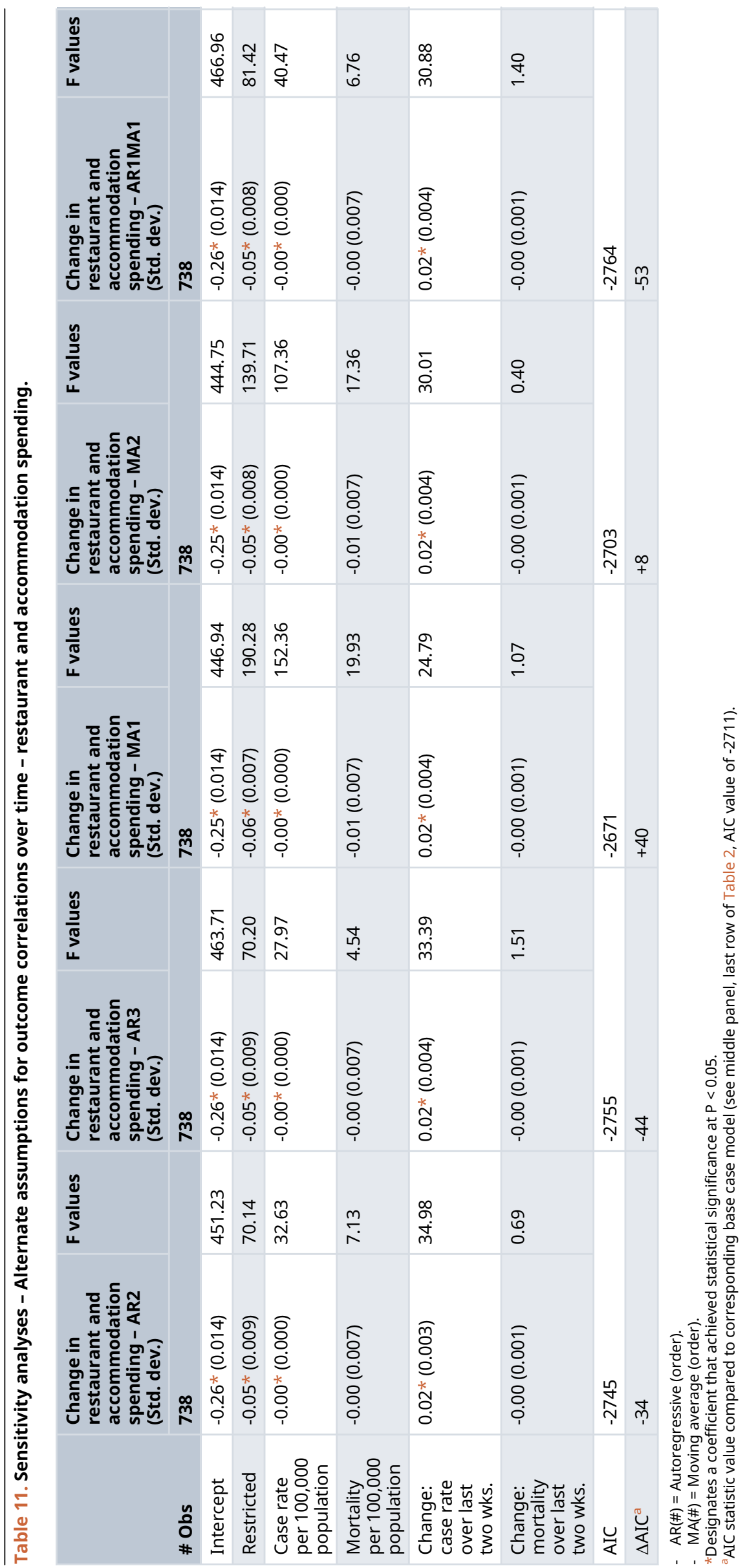




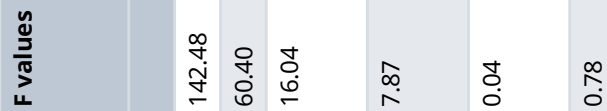
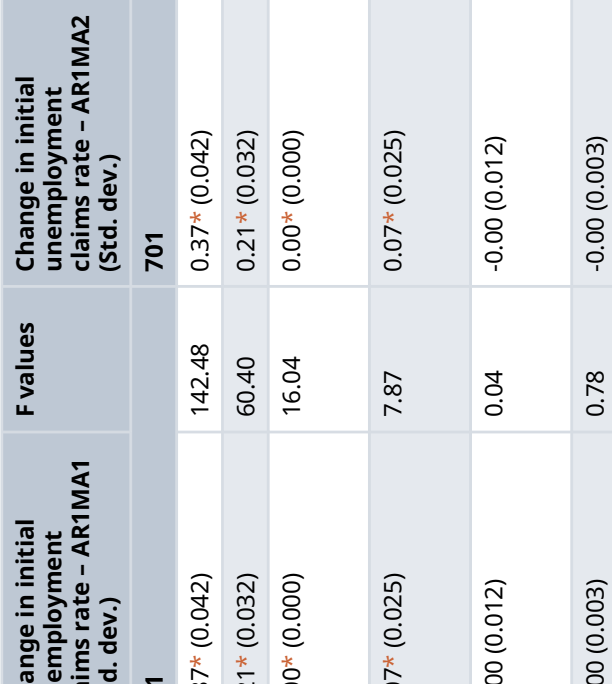

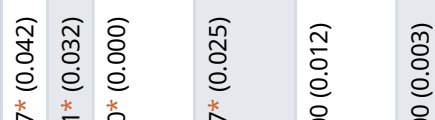

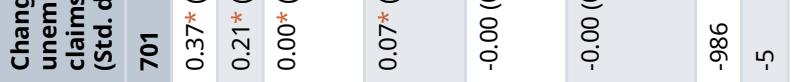

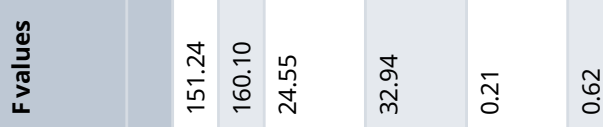

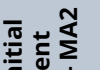

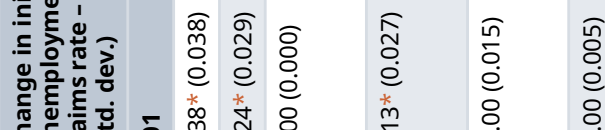

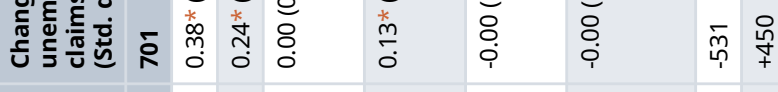

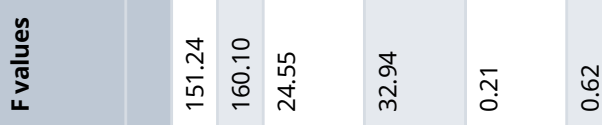

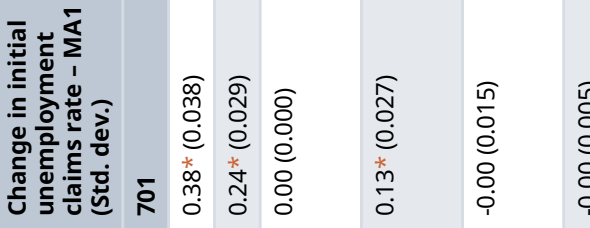

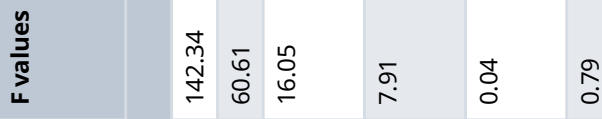

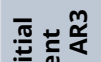

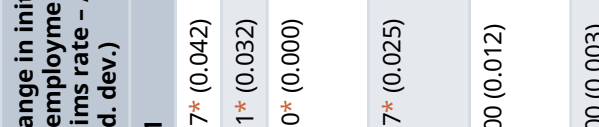

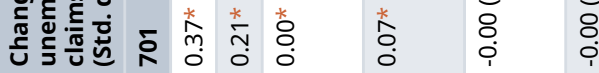

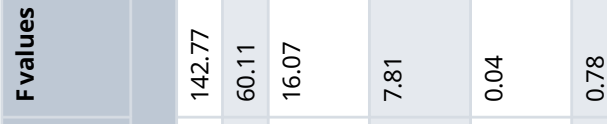

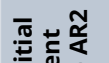

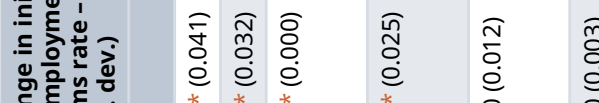

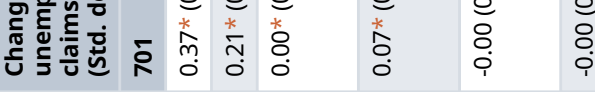

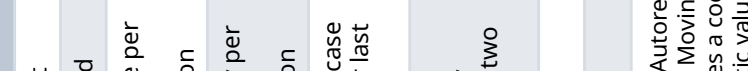

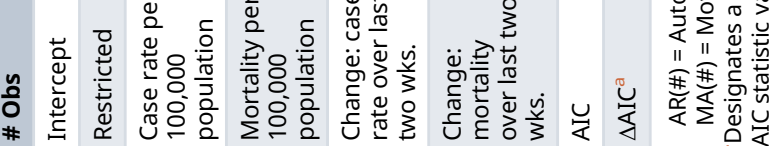


definitions for government restrictions suggest, however, that this issue does not invalidate our findings. A second complication is the fact that government-imposed restrictions tend to coincide with the events that cause voluntary reductions in economic activity. In short, the same news headlines that cause state governments to impose restrictions also cause many consumers to voluntarily stay home and reduce their spending. We attempted to isolate the impact of government-imposed restrictions by including in our models daily COVID cases and mortality, and the changes in those statistics over the preceding two weeks.

We estimated the dollar cost of restrictions as follows. Our base case analysis results imply that restrictions reduce consumer spending by $2 \%$, reduce restaurant and accommodations spending by $5 \%$, and increase weekly unemployment claims by $0.21 \%$ of the 2019 work force. Nationally, total annualized consumer spending amounted to $\$ 13.3$ trillion in the fourth quarter of $2019 ;{ }^{23}$ restaurant and accommodations spending totals approximately $\$ 1.2$ trillion annually, including $\$ 863$ billion spent in restaurants ${ }^{24}$ and $\$ 300$ billion spent on accommodations. ${ }^{25}$ The U.S. labor force in 2019 totaled 163 million individuals. ${ }^{26}$ The model results hence imply that restrictions, if imposed by all states for a full year, would reduce total consumer spending by $2 \% \times 13.3$ trillion $\approx 270$ billion, of which $5 \% \times 1.2$ trillion $=60$ billion could be attributed to a reduction in spending on restaurants and accommodations. The model results also imply that restrictions imposed by all states would increase initial weekly unemployment claims by $0.21 \% \times 163$ million $\approx 340,000$ initial claims each week.

The computations just described yield cost estimates for a hypothetical, nationwide, year-long imposition of business restrictions. We scale these estimates down to characterize the impact of the restrictions actually imposed. During the fall and winter of 2020-2021, when the U.S. experienced the pandemic's third wave, 10 states (CA, IL, KY, MI, MN, NM, OR, PA, RI, and WA) imposed restrictions for between 21 and 86 days, with an average (and GDP-weighted average) duration of 49 days. Those states represent approximately one-third of the country's GDP. ${ }^{27}$

Taking a third of the projected nationwide, annual costs ( $\$ 90$ billion for total spending and $\$ 20$ billion for restaurant and accommodations spending), and then scaling these values down by a further 86.5 percent to impute the costs associated with the imposition of restrictions for 7 weeks (13.5 percent the year) yields costs of $\$ 12$ billion in total consumer spending, of which $\$ 2.7$ billion would be attributable to decreased spending on restauraunts and accommodations. Assuming employment is approximately proportional to GDP, these states would together experience an additional 114,000 initial weekly unemployment claims each week during the imposition of these restrictions. (We note that the unemployment data do not reflect seasonal adjustment, but it is not evident that this limitation introduces any particular bias; nonetheless, it does introduce some uncertainty.)

While a total cost of $\$ 12$ billion can seem modest in the context of a global pandemic with estimated costs likely amounting to trillions of dollars in lost economic activity, the losses estimated here are indeed substantial. Keep in mind that they occur over a limited time period (during the 1 or 2 months at the peak of a surge in COVID cases) and that the population can experience multiple case surges during a pandemic; as of this writing, the United States has experienced three such surges and is in the midst of a fourth due to the Delta variant. Assuming that late 2020 is representative of tendencies for the government to restrict economic activity in response to high hospital utilization, therapies reducing hospital utilization have the potential to confer substantial societal value.

Whether prices charged for therapies should reflect this component of value is another question, as decision makers must also consider a range of issues, including affordability. ${ }^{28}$ Importantly, this analysis shows that estimating the cost of government-imposed restrictions is feasible, hence making it possible to extend health technology assessments beyond the typical and often exclusive focus on the valuation of health benefits.

\section{Conclusions}

Government restrictions reduced consumer spending by 12 billion dollars and increased unemployment claims by 114,000 each week during the Fall/early Winer surge of COVID-19. Sensitivity analysis showed these findings to be robust to alternative modeling assumptions. The criteria for implementing business restrictions in various U.S. states, such as California and New York, suggest that increases in hospital utilization during COVID pandemic surges trigger such government restrictions. As COVID-19 therapies that can lower the risk of hospitalization and severe disease are developed and become available, government business restrictions may become a less necessary measure for lowering the hospital burden. Therefore, our analysis suggests that investment in the development and use of such therapies may not only provide a substantial health benefit, but also avert some of the economic impact of government restrictions, providing a substantial societal benefit. 
While a therapy's health benefits will no doubt remain the core element of health technology assessment, for therapies addressing threats that affect others in addition to those who become ill, recognizing societal benefits will help allocate resources to promote innovations that address the most important risks society faces.

\section{Data availability statement}

Repository: CEVR---Consortium---COVID-19

https://github.com/sweidner1/CEVR---Consortium---COVID-19-

This project contains the following underlying data:

- Generated Data for Analysis - Spending.csv - Data file containing weekly observations of business restrictions data for each state.

- Generated Data for Analysis - Unemployment.csv - Data file containing weekly observations of business restrictions data for each state.

- Data Cleaning. $\mathrm{R}-\mathrm{R}$ code file that takes raw data files and cleans them into files suitable for analysis using our model.

- Base Case. $\mathrm{R}$ - R code file that completes our base case regression analysis for all three outcomes and produces results files.

- Table $1 . \mathrm{R}-\mathrm{R}$ code file that generates summary statistics for our data and produces results files.

- Table A2.R - R code file that completes our ten state subgroup regression analysis for all three outcomes and produces results files.

- Table A3a. R - R code file that completes our sensitivity analyses in which we remove case rate, death rate, and both as explanatory variables for the total consumer spending outcome and produces results files.

- Table A3b. R - R code file that completes our sensitivity analyses in which we remove case rate, death rate, and both as explanatory variables for the restaurant and accommodation spending outcome and produces results files.

- Table A3c. $\mathrm{R}$ - R code file that completes our sensitivity analyses in which we remove case rate, death rate, and both as explanatory variables for the initial unemployment claims outcome and produces results files.

- Table A4a. R - R code file that completes our sensitivity in which we alter the definition of our business restrictions variables Restricted for the total consumer spending outcome and produces results files.

- Table A4b. R - R code file that completes our sensitivity in which we alter the definition of our business restrictions variables Restricted for the restaurant and accommodation spending outcome and produces results files.

- Table A4c. $\mathrm{R}-\mathrm{R}$ code file that completes our sensitivity in which we alter the definition of our business restrictions variables Restricted for the initial unemployment claims outcome and produces results files.

- Table A5a. R - R code file that completes our sensitivity in which we vary out assumptions for outcome correlations over time for the total consumer spending outcome and produces results files.

- Table A5b. R - R code file that completes our sensitivity in which we vary out assumptions for outcome correlations over time for the restaurant and accommodation spending outcome and produces results files.

- Table A5c. $\mathrm{R}-\mathrm{R}$ code file that completes our sensitivity in which we vary out assumptions for outcome correlations over time for the initial unemployment claims outcome and produces results files.

- README.docx - README file that gives further details on all data files and describes how to properly run all code files to replicate our analysis 
Data are available under the terms of the Creative Commons Zero "No rights reserved" data waiver (CC0 1.0 Public domain dedication).

\section{Repository: Opportunity Insights Economic Tracker}

https://github.com/OpportunityInsights/EconomicTracker

This project contains the following underlying data:

- Affinity - State - Daily.csv - Data file containing daily observations of spending statistics for each U.S. state, including \% change in total consumer spending since January 2020, and \% change in restaurant and accommodation spending since January 2020.

- COVID - State - Daily.csv - Data file containing daily observations of COVID statistics for each U.S. state, including new case rate and new death rate.

- UI Claims - State - Weekly.csv - Data file containing weekly observations of unemployment claims statistics for each U.S. state, including initial weekly unemployment claims rates.

Repository: STROBE checklist for "The cost of business restrictions during the COVID-19 pandemic" https://github.com/sweidner1/CEVR---Consortium---COVID-19-

This project contains the following underlying data:

- 202108 03a - STROBE checklist.docx - Word document containing the STROBE (Strengthening the Reporting of Observational Studies in Epidemiology) reporting guidelines checklist with all relevant information from our manuscript to show fulfillment of the checklist.

Data are available under the terms of the Creative Commons Zero "No rights reserved" data waiver (CC0 1.0 Public domain dedication).

1. Fernández-Villaverde J, Jones C: Macroeconomic outcomes and COVID-19: A progress report. Cambridge, MA; 2020 October.

2. Chatterii P, Yue L: Effects of the COVID-19 Pandemic on Outpatient Providers in the US: National Bureau of Economic Research. 2020.

3. Ziedan E, Simon K, Wing C: Effects of state COVID-19 closure policy on non-COVID-19 health care utilization: National Bureau of Economic Research; 2020. Report No.: Working Paper 27621.

4. Mehrotra A, Chernew M, Linetsky D, et al.: The Impact of COVID-19 on Outpatient Visits in 2020: Visits Remained Stable, Despite a Late Surge in Cases: The Commonwealth Fund. 2021 February 22.

5. Agostinelli F, Matthias D, Sorrenti G, et al.: When the great equalizer shuts down: Schools, peers, and parents in pandemic times: National Bureau of Economic Review; 2020. Report No.: Working Paper 28264.

6. Neumann PJ, Cohen JT, Kim DD, et al.: Consideration Of ValueBased Pricing For Treatments And Vaccines Is Important, Even In The COVID-19 Pandemic. Health affairs (Project Hope). 2021; 40: 53-61.

PubMed Abstract | Publisher Full Text

7. Acharya $\mathrm{V}$, Johnson $\mathrm{T}$, Sundaresan $\mathrm{S}$, et al.: The value of a cure: An asset pricing perspective: National Bureau of Economic Research; 2021. Report No.: Working Paper 28127.

8. Shorrocks A, Davies J, Lluberas R:Credit Suisse Research Institute: Wealth of Nations; 2020.

9. U.S. Food and Drug Administration: FDA Approves First Treatment for COVID-19. 2020
10. U.S. Food and Drug Administration: Coronavirus (COVID-19) Update: FDA Authorizes Monoclonal Antibody for Treatment of COVID-19. 2020.

11. Gavin K: Flattening the Curve for COVID-19: What Does It Mean and How Can You Help? University of Michigan; 2020.

12. Roberts S: Flattening the Coronavirus Curve. New York Times. 2020 March; 27.

13. Tampone K: If NY hospitals get overwhelmed, state could shut down again, Cuomo says. Syracusecom. 2020 November 30.

14. Cowan J: California's Governor Warns of 'Drastic Action' as Hospitals Near Crisis. New York Times. 2020 November 30.

15. Pan E: Regional Stay At Home Order 12/03/2020. State of California-Health and Human Services Agency - California Department of Public Health; 2020.

16. NBC10Boston: Massachusetts Is Easing Some COVID Restrictions Next Week. Here's What to Know. 2021.

17. Cox J: Jobless claims fall again as employment picture gains strength. CNBC. 2021.

18. Kerstein S: U.S. Retail Sales Update. Legislative Analyst's Office. September 2020: 2020.

19. Chetty R: Opportunity Insights Economic Tracker. Opportunity Insights: Harvard University; 2021

20. The Economic Impacts of COVID-19: Evidence from a New Public Database Built Using Private Sector Data", by Raj Chetty, John Friedman, Nathaniel Hendren, Michael Stepner, and the 
Opportunity Insights Team. November 2020. Reference Source

21. The New York Times: See Coronavirus Restrictions and Mask Mandates for All 50 States. New York Times. 2021.

22. The New York Times: nytimes/covid-19-data. 2021.

23. United States Consumer Spending: 2021. Reference Source

24. National Restaurant Association: Restaurant Industry Factbook. 2019: 2019.
25. US Bureau of Commerce - International Trade Administration: Travel, tourism \& hospitality spotlight. The Travel, Tourism and Hospitality Industry in the United States; 2018.

26. Monthly Labor Review: 2020.

Reference Source

27. US Bureau of Economic Analysis: Gross Domestic Product by State. 4th Quarter and Annual 2019. 2020.

28. Cohen JT, Neumann PJ, Ollendorf DA: Valuing And Pricing Remdesivir: Should Drug Makers Get Paid For Helping Us Get Back To Work? Health Affairs Blog. 2020. 


\section{Open Peer Review}

\section{Current Peer Review Status: ? ?}

Version 1

Reviewer Report 22 November 2022

https://doi.org/10.5256/f1000research.59228.r154440

(C) 2022 Kantur Z. This is an open access peer review report distributed under the terms of the Creative Commons Attribution License, which permits unrestricted use, distribution, and reproduction in any medium, provided the original work is properly cited.

\section{Zeynep Kantur}

Department of Economics, Başkent University, Ankara, Turkey

This paper investigates the impact of government restrictions during the COVID-19 pandemic (Sep. 2020-Dec. 2020) on credit and debit card (consumer spending) spendings, and initial unemployment claims in United States using state-level data. The main idea of the paper is to quantify the cost of government restrictions on economic activity and compare it with the cost of COVID-19 therapies. According to the findings of the analysis, government-imposed restrictions lead to a decline in both total consumer spending and restaurant and accommodation spendings, and an increase in the initial unemployment claims. The results of the base case analysis suggest that restrictions reduce consumer spending by $2 \%$, restaurant and accommodation spendings by $5 \%$, and increase weekly unemployment claims by $0.21 \%$. These results are robust to alternative model specifications. The manuscript is well written, but a few aspects need improvement. I have some suggestions on this.

1. The data should be explained in detail. Consumer spending in this paper is credit and debit card data which raises the following questions: How is the data collected? Is it collected from the banks, which includes information at the household level, or is it gathered from the POS machines (including virtual ones) of all banks operating in the U.S.? Does it include online transactions? If this is the case, then state-level analysis could be misleading since households can carry out their transactions outside their states. In other words, does the card data take into account the location of the household or the place of purchase? The authors should mention online spending since restrictions had a very limited impact on it.

2. Although government restrictions reduce consumer spending, this is not the only reason. Expenditures also provide information about income level. Households may reduce their consumption due to fear of losing, or losing, their job during the COVID-19 period. The analysis itself confirms this in the initial unemployment claims analysis. The study should definitely talk about this issue. Households spend out of existing income/wealth with the debit, a consumer spends also out of expected future income/wealth with the credit card.

3. Mobility restrictions (which are not mentioned in the paper) might have directed some of the spendings that would otherwise be paid in cash to online providers that require 
credit/debit card transactions. This is not necessarily a change in the consumption level for those products; in fact, it is again a change in payment methods. I suggest authors check the Google mobility index which is available at the state level.

4. What is the level of credit/debit card used in each state?

5. Following my point on income, did government financial support programs differentiate at the state level? If it is the case, it should be included in the analysis.

I have some minor comments.

1. I think the empirical findings fall short in terms of commenting on a comparison of health therapies and the economic cost of restrictions.

2. Since the article is motivated by the cost/benefit of health therapies, I found nothing about them in the article. Some information would be beneficial for readers.

3. In Table 3. The Restricted is not statistically significant. But in the text, it says the base case analysis and 10-state analysis have the same findings.

4. There is a typo in the first sentence of the Conclusion section. ('Winter')

Is the work clearly and accurately presented and does it cite the current literature? Yes

Is the study design appropriate and is the work technically sound? Partly

Are sufficient details of methods and analysis provided to allow replication by others? Yes

If applicable, is the statistical analysis and its interpretation appropriate? Yes

Are all the source data underlying the results available to ensure full reproducibility? Yes

Are the conclusions drawn adequately supported by the results? Partly

Competing Interests: No competing interests were disclosed.

Reviewer Expertise: Economics

I confirm that I have read this submission and believe that I have an appropriate level of expertise to confirm that it is of an acceptable scientific standard, however I have significant reservations, as outlined above. 
Reviewer Report 29 March 2022

https://doi.org/10.5256/f1000research.59228.r129099

(C) 2022 Dexter $\mathbf{F}$. This is an open access peer review report distributed under the terms of the Creative Commons Attribution License, which permits unrestricted use, distribution, and reproduction in any medium, provided the original work is properly cited.

\section{Franklin Dexter}

Division of Management Consulting, Department of Anesthesia, University of Iowa, Iowa City, IA, USA

How does one value vaccine or therapy to treat SARS-CoV- 2 in terms of the impact on an economy? One mechanism is its prevention of hospitals filling and State or Provincial governments then choosing to shut down parts of the economy (e.g., restaurants and other service industries). In this paper, the authors estimate the economic cost of such a shut-down. From the authors' conclusions, "therapies reducing hospital utilization have the potential to confer substantial societal benefit." Much of the supply of patients staying longer than overnight are inpatient surgical patients, only one-third of all surgery. Overnight stays routinely are without hospital admission, rather than using the surgical recovery rooms. Therapies reducing hospital utilization then are those anesthetic treatments that convert 2- or 3-day hospital stays to overnight.

While the Introduction and Methods are reasonable, I have two related statistical concerns that affect the results (e.g. Table 2 ) and the interpretation/application of those results in the Discussion where the authors draw their conclusions.

Major concerns:

The authors' economic analysis and conclusions on page 14 reasonably depend on the base case analysis. The table has more than 10 comparisons. I do not understand the rationale for using $\mathrm{P}<0.05$ without consideration of the multiple comparisons. Whether the authors consider a reduction in consumer spending by $2 \%$ (P14, paragraph 2) based on parameter uncertainty or based on the sensitivity analyses, just using $2 \%$ in the economic analyses on page 14 seems limited.

The authors do not rely on page 14 on the confidence interval for the $2 \%$. The authors also do not include standard error (or equivalent) for the 1.2 trillion on page 14, paragraph 2 . Therefore, the "by 12 billion dollars" on page 14, last paragraph does not account for uncertainty in the estimate. Please add consideration of uncertainty quantitatively on page 14, and then the abstract.

\section{Minor concern:}

Finally, I do not follow the "Taking a third" in the fourth paragraph of page 14.

\section{Is the work clearly and accurately presented and does it cite the current literature?}


Yes

Is the study design appropriate and is the work technically sound?

Yes

Are sufficient details of methods and analysis provided to allow replication by others? Yes

If applicable, is the statistical analysis and its interpretation appropriate? Partly

Are all the source data underlying the results available to ensure full reproducibility? Yes

Are the conclusions drawn adequately supported by the results?

Partly

Competing Interests: No competing interests were disclosed.

Reviewer Expertise: Operating room and anesthesia group administrative modeling

I confirm that I have read this submission and believe that I have an appropriate level of expertise to confirm that it is of an acceptable scientific standard, however I have significant reservations, as outlined above.

The benefits of publishing with F1000Research:

- Your article is published within days, with no editorial bias

- You can publish traditional articles, null/negative results, case reports, data notes and more

- The peer review process is transparent and collaborative

- Your article is indexed in PubMed after passing peer review

- Dedicated customer support at every stage

For pre-submission enquiries, contact research@f1000.com 